\title{
Do Trees Grow on Money? The implications of deforestation research for policies to promote REDD
}

\author{
Markku Kanninen, Daniel Murdiyarso, Frances Seymour, Arild Angelsen \\ Sven Wunder and Laura German
}

\section{Key points}

- Emissions from deforestation and degradation account for about 20 per cent of global carbon emissions. A financing mechanism for reducing emissions from deforestation and forest degradation (REDD) is therefore likely to be part of the climate protection regime that will succeed the Kyoto Protocol, which ends in 2012.

- The success of REDD in reducing emissions will depend on tackling profound market and governance failures. REDD policies will have to align the incentives of economic actors and the public interest, a challenge made more difficult by the complex causes of deforestation, many of which are external to the forestry sector.

- Policies need to address diverse local situations while removing perverse subsidies that encourage forest conversion, ending unsustainable extraction, devolving rights and responsibilities to local forest users and promoting the benefits and ecosystem services that forests provide besides carbon storage and sequestration.

\section{Forestry, land use change and carbon emissions}

Forests are receiving a level of international attention not seen since the 1992 Earth Summit. The 2006 Stern Review was compelling in reminding policy makers of the important linkages between forests and climate: One fifth of total annual carbon emissions now come from land-use change, most of which involves tropical deforestation. Every year around 13 million hectares of forest are lost, and deforestation now adds more carbon to the atmosphere than the global transport sector. The world can no longer afford to ignore the role of deforestation in global warming.

Every year land-use changes release an estimated 6 billion tons of carbon dioxide, most of it through tropical deforestation. Yet avoidance of deforestation was not on the list of activities eligible for the Clean Development Mechanism agreed at the Marrakesh Accords in 2001 (UN Framework Convention on Climate Change, Conference of the Parties 7). The decision not to include deforestation in this financing mechanism resulted from concerns about leakage (increased emissions outside project boundaries), additionality (unsolved issues of baseline emissions levels) and how to establish baseline (or reference) levels of emissions.

Most causes of deforestation lie outside the forestry sector. Understanding them is crucial to identifying appropriate incentives to curb deforestation. Financing REDD may require significant international funding. 


\section{Deforestation and degradation}

In addition to contributing to climate change, deforestation causes loss of biodiversity, flooding, siltation and soil degradation. It threatens the welfare of forest-dependent people as well as the future supply of the forest's products. Although definitions of both deforestation and degradation and methods for assessing them vary, the United Nations Food and Agriculture Organisation estimates that for the period 2000-2005 the net annual loss of forests (deforestation offset by regenerating forests and the expansion of tree plantations) averaged 7.3 million hectares.

The highest absolute losses are in South America, followed by Africa. The highest losses as a proportion of remaining forest area are in Central America and Southeast Asia. Agreement on definitions and harmonisation of cost-effective monitoring systems and methods for setting agreed reference levels will become more important as policy initiatives focus on REDD.

Deforestation may be defined as long-term or permanent conversion of land from forest to non-forest uses. Effectively this definition means a reduction in crown cover below a given threshold, typically 10 per cent. The term specifically excludes areas where the trees have been temporarily removed as a result of harvesting or logging and where the forest is expected to regenerate naturally or with the aid of silvicultural measures.

In the context of the REDD debate, degradation is defined as a loss of carbon in forests, including emissions from forests caused by a decrease in canopy cover that does not qualify as deforestation.

\section{Causes of deforestation and degradation}

Deforestation and degradation are caused by either direct causes, those directly linked to clearing or degrading land, or underlying causes, the background societal factors that drive direct causes. Another distinction is between deforestation/degradation driven by causes originating within the forest sector (intrasectoral factors) and activities driven by causes originating from other sectors (extra-sectoral factors).

The three main direct causes of deforestation and forest degradation are agricultural expansion (including grazing), wood extraction and infrastructure extension. Forest fires also cause deforestation and forest degradation, and their frequency and intensity are increasing due to the impacts of climate change. The underlying causes of deforestation and forest degradation can be grouped under macroeconomic, governance and other factors.

Analysis of deforestation in 152 countries suggests that the three direct causes of deforestation interact with five principal underlying causes: demographic, economic, technological, policy and cultural variables. In the Amazon Basin, forests are cleared for beef and soybean production, while in Southeast Asia deforestation results from development of oil-palm plantations by large-scale industrial tree farms. Demand from China for pulpwood and from Europe and domestic markets for palm oil caused the deforestation or degradation of almost half the carbonrich peatlands of Southeast Asia between 1996 and 2006.

Wood extraction is the main intra-sectoral cause of deforestation, though reduced-impact logging can both minimise damage and reduce the chances that logging will lead to conversion to other land uses. Uncontrolled extraction and poor logging practices often lead to degradation and deforestation. Road construction facilitates in-migration and conversion to agriculture, especially where property rights are unclear or poorly enforced. Degraded forest may be abandoned or designated for conversion to other uses.

Clear-cutting for pulpwood and logging, sometimes illegal, have been major causes of deforestation in Southeast Asia, whereas unsustainable fuelwood extraction and charcoal production predominate in sub-Saharan Africa. Though road construction accounts for small amounts of direct forest clearance, the consequent reduction of transport costs can stimulate other activities that result in further clearance.

Of the underlying causes, economic growth may initially increase deforestation for agricultural production. But pressures on forests may decline as agricultural production becomes intensive, service sectors become more important and demand for forest products and services rises. Other macroeconomic factors that can affect forests include external debt, foreign exchange-rate policy, trade policies, support for expansion of forest-product industries and economic crises.

Governance factors play a major role in determining what happens to forests. Secure property rights and effective local institutions are needed for investment in sustainable forest management. However, secure rights can encourage conversion of forest to more profitable use, so they are only an effective tool for REDD when combined with economic incentives to raise the profitability of forest conservation. Without transparent decision-making, a clear and strongly enforced 


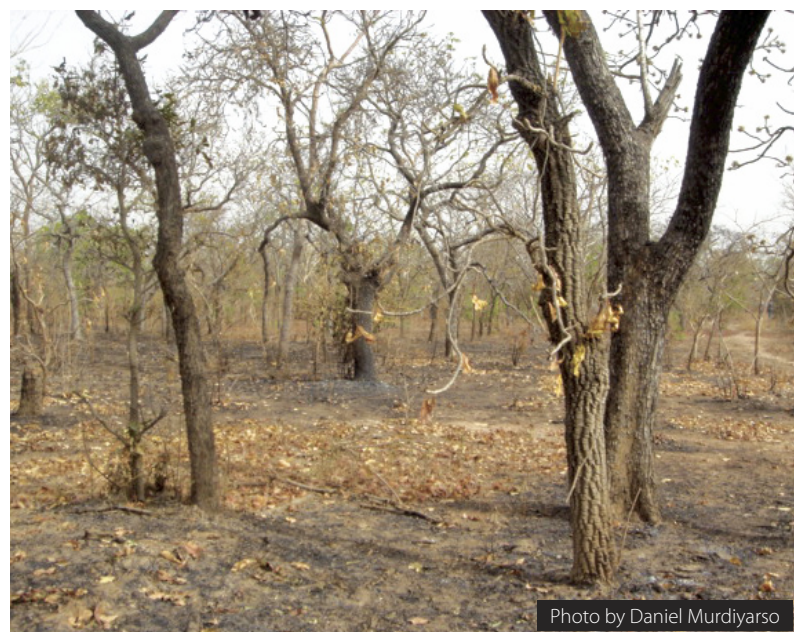

legal framework and effective decentralisation, it is easier for unscrupulous national and local elites to manipulate forest protection policies to their own benefit. Widespread corruption often neuters public accountability.

In addressing these multi-dimensional causal factors, REDD schemes must recognise that there can be no 'one size fits all' approach. Because it is impossible to predict all the macroeconomic factors or devise policy interventions for them, the level of forest protection offered by REDD policies will be equally uncertain. In pursuit of economic growth and poverty reduction, governments may see the conversion of forests to other uses as appropriate, so REDD schemes will need to provide convincing economic alternatives. A central question is whether the prospect of a global REDD regime will encourage governance reforms that give forest protection higher priority at the expense of the interests of privileged political and economic elites.

\section{Reducing deforestation and degradation}

In analysing policies to abate deforestation, it is useful to distinguish between 'appropriate' and 'inappropriate' deforestation - even if their application is seldom clear-cut. In 'appropriate' deforestation, lowutility forest may be converted to provide higher or longer-lasting benefits.

'Inappropriate' deforestation occurs when forest with important economic values or high biodiversity is converted to a less suitable use. A global REDD regime would alter the calculus of what is most appropriate in any particular place, using a combination of economic and financial instruments, direct regulation, and governance and institutional strengthening. All the factors described below have a bearing on the design and implementation of REDD strategies.
To reduce the profitability of alternative land use, it's possible to internalise the harmful environmental impacts of forest conversion, eliminate subsidies that raise returns from unsustainable logging and conversion, and create positive incentives for forest protection and sustainable use. Corrective economic and financial incentives include lower tax rates on conserved forest land; certification schemes and targeted investment flows that reward beneficial activities; and transfer payment schemes for specified actions that constitute an environmental service. For instance, payments for ecosystem services (PES) could be made for carbon sequestration and storage, biodiversity conservation, watershed protection or retention of landscape beauty.

None of these instruments can be effective unless forest actors have secure tenure to the land and control over its resources. Where such conditions do not exist, direct regulation of forest use may be necessary. This includes making conversion or degradation illegal by setting up national parks, zoning land use, banning logging or burning, and prohibiting road construction. However, complex regulation can increase opportunities for corruption.

Though secure land tenure is needed to attract longterm investment in sustainable forest use, some property regimes require forest clearance in return for securing property rights. Such perverse incentives should be eliminated, and where tenure is insecure, resolving it should be conditioned upon sustainable forest management. Readily available information and transparent procedures involving all stakeholders are necessary to improve the integrity of decision-making and hold government agencies and private companies to account.

The capacity of a government to design, implement and enforce policies is key to ensuring their effectiveness. Insufficient devolution of forest management authority has hindered some reforms. Strengthening local rights to forest resources needs to be matched by adequate local governance capacity and the right incentives.

\section{Implications for policies and further research to support REDD}

The complex interplay of social, economic, environmental and political factors makes it difficult to generalise about appropriate responses to the various causes of forest loss and degradation. Responses must be tailored to specific contexts, but all have to address the simple fact that forests are being converted or degraded because such activity earns a higher 
economic return to the land user than maintaining them as forests.

Much data on forest cover, deforestation and degradation are still unreliable. More robust and internationally agreed definitions, systems and methods will be needed to monitor changes in forest carbon stocks. Though new technology exists to remedy the deficit, capacity at the national level must be assessed, and improved where necessary. Reaching agreement on baselines and reference levels will not be easy, as it will be in each country's interest to establish a high baseline to maximise REDD financial transfers. REDD programmes cannot influence macrolevel drivers of deforestation, such as population growth and exchange rate movements, so methods used to determine baselines must be able to cope with uncertainty.

For nationally applied REDD schemes, the priorities for further research on reference levels and baselines development are:

- Analysis and modelling of historical changes in forest cover

- Analysis of the extent to which such models are able to represent the future projection of biophysical and socio-economic parameters in a given REDD scheme

- Analysis of the importance of the geographic scale of the assessment (e.g., national versus sub-national) of national reference levels

Prominent among REDD policy options are direct transfer payments, and more research is needed on the necessary conditions for PES schemes to be effective, efficient and equitable. Research is also needed on how such schemes can integrate multiple ecosystem services such as carbon storage and watershed protection and on the best ways to clarify and secure forest tenure. REDD programmes must incorporate long-term efforts to create and reform institutions, strengthen government processes and build the capacity to implement new models of forest management. Their design and implementation will require trade-offs among efficiency, effectiveness, fairness and risk. Should resources be directed to situations with the greatest potential for reducing emissions or poverty? Should REDD proceed where there is a high risk of funds being lost to corruption? Such political decisions need to be informed by scientific research and economic analysis.

Successful implementation of REDD schemes will often require strengthening the stake of local communities in protecting forest assets to allow them to match the power of larger actors. Judicial systems need strengthening to combat illegal forest exploitation. International cooperation is required to address the demand for illegally produced wood products. To oversee payments under REDD schemes, governments will need to create new institutions. A key challenge will be to ensure payments are made to those who control what happens to the forest. All of these actions will have consequences with diverse impacts on the often conflicting needs of stakeholders. Balancing them will require a robust and flexible REDD mechanism.

For further information, please contact:

Markku Kanninen m.kanninen@cgiar.org

Daniel Murdiyarso d.murdiyarso@cgiar.org

Frances Seymour f.seymour@cgiar.org

Arild Angelsen arild.angelsen@umb.no

SvenWunder s.wunder@cgiar

Laura German I.german@cgiar

A full length version of the paper can be found at:

http://www.cifor.cgiar.org/Publications/Detail?pid=2347

For general inquiries, contact cifor@cgiar.org

Center for International Forestry Research (CIFOR) advances human well-being, environmental conservation, and equity by conducting research to inform policies and practices that affect forests in developing countries. CIFOR is one of 15 centres within the Consultative Group on International Agricultural Research (CGIAR). CIFOR's headquarters are in Bogor, Indonesia. It also has offices in Asia, Africa and South America. CIFOR works in over 30 countries worldwide and has links with researchers in 50 international, regional and national organisations. www.cifor.cgiar.org 